\title{
Chronic Neck Pain Assessment using Multi-Frequency Bioimpedance
}

\author{
Dilay Kesgin Fener ${ }^{1^{*}}$, Else Marie Bartels ${ }^{1}$, Vibeke Sodring Elbrønd ${ }^{2}$ and Adrian Paul Harrison ${ }^{2}$ \\ ${ }^{1}$ The Parker Institute, Copenhagen University Hospital, Bispebjerg and Frederiksberg, Denmark \\ ${ }^{2}$ IKVH Faculty of Health \& Medical Sciences, Copenhagen University, Denmark
}

\begin{abstract}
Summary
Scope: Chronic neck pain (CNP) is a disabling condition where the cause is often unknown, making treatment difficult. Muscle involvement is suspected in most cases, and assessment of muscle condition and changes following treatment may be possible with multi-frequency bioimpedance (mfBIA). Our aim was to test mfBIA as an assessment method of possible involvement of the neck, back and other related muscles in two CNP patients, prior to and following physiotherapy treatment with AtlasBalans.
\end{abstract}

Methods: mfBIA measurements were carried out pre-treatment on $\mathrm{m}$. sternocleidomastoideus, $\mathrm{m}$. trapezius, upper back, lower back, $m$. vastus lateralis, and $m$. gastrocnemius. Centre frequency (fc), extracellular Resistance $(\mathrm{Re})$ and intracellular Resistance (Ri), Impedance (Z), Resistance (R) and Reactance (XC) were measured, and Phase Angle (PA) and Membrane Capacitance (Mc) were calculated, using ImpediMed Inc software. AtlasBalans treatment was carried out on $\mathrm{m}$. sternocleidomastoideus and $\mathrm{m}$. trapezius with following mfBIA measurement of these. Relationship between Z, R, fc, Ri and Mc was studied pre and post-treatment.

Results: The $Z$ and $R$ data suggested no great degree of inflammation or overuse of the measured muscles. The fc data indicate muscle involvement with elevated resting tension and imbalance between the left and right sides. Ri and Mc confirm the interpretation of imbalance, indicating an elevated metabolic activity in some muscles.

Conclusion: mfBIA seems a promising method to follow muscle involvement in chronic neck pain patients. AtlasBalans treatment did not show any clear indication as being an efficient form of treatment to relieve muscle tension in CNP patients.

Keywords: Bioimpedance; Neck pain; Symptom assessment; Therapy

Abbrevations: CN: Chronic Neck Pain; mfBIA: Multi-frequency Bio impedance; fc: Centre Frequency; Re Extracellular Resistance; Ri: Intracellular Resistance; Z: Impedance; R: Resistance; Xc: Reactance

\section{Introduction}

Chronic neck pain (CNP), where a period of neck pain develops into what can be defined as a chronic condition, is common [1-3]. To be chronic, the pain has to persist for a 3 month period after onset.

CNP creates disability and affects the sufferer's quality of life [4-6]. It also has severe economic consequences for those individuals affected, as well as for society in general $[7,8]$.

The prevalence of CNP is found to be between 1.7 and $11.5 \%$ for activity-limiting neck pain existing for a period of 12 months after onset. Furthermore, even for those individuals in the group capable of participating in their normal daily activities, a mild chronic pain may still persist [3].

The fact that there is often no objective measure to indicate the cause of the experienced CNP, adds to the stress to which CNP patients are exposed when prognosis of disease development and choice of treatment are considered.

Multi-frequency bioimpedance ( $\mathrm{mfBIA}$ ) is able to give an immediate description of the condition of a muscle [9], and has recently been shown to provide details regarding muscle resting tension and cellular activity, as well as training level and recovery rate following muscle injury $[9,10]$. Since there are indications that CNP can be improved with physical therapy and manipulation [11-16], muscle involvement is very likely in most cases.

Our aim was to test whether mfBIA as a method of assessing the possible involvement of the neck, back and other related muscles (myofascial trains [17]), when presented with a CNP patient, allows the user to follow a suspected involvement of a particular muscle after physical therapy treatment following application with the AtlasBalans method (AtlasBalans AB, Stockholm, Sweden).

Our hypothesis was that CNP, caused in part by muscle changes, e.g. excessive and constant compensatory muscle tension arising from a minor or major injury to the neck or other related region/s of the body, can be monitored in real-time using mfBIA.

\section{Materials and Methods}

\section{Participants}

Two cases of CNP were studied.

1. A 53 year old woman, weight $70 \mathrm{~kg}$, height $1.65 \mathrm{~m}$, who following a fall from a horse 3 years previous to the measurement had experienced continuous neck pain affecting her daily routine and work ability.

2. A 41 year old woman, weight $68 \mathrm{~kg}$, height $1.78 \mathrm{~m}$, who had been involved in a bicycle accident and had, subsequently, experienced chronic neck pain that affected her daily routine with particular focus on transportation.

*Corresponding author: Fener DK, Bartels EM, Elbrond VS, Harrison AP (2016) Chronic Neck Pain Assessment using Multi-Frequency Bioimpedance. Physiother Rehabil 1: 113. doi:10.4172/2573-0312.1000113

Received: May 04, 2016; Accepted: June 09, 2016; Published: June 16, 2016

Citation: Fener DK, Bartels EM, Elbrond VS, Harrison AP (2016) Chronic Neck Pain Assessment using Multi-Frequency Bioimpedance. Physiother Rehabil 1: 113. doi: $10.4172 / 2573-0312.1000113$

Copyright: @ 2016 Fener DK, et al. This is an open-access article distributed under the terms of the Creative Commons Attribution License, which permits unrestricted use, distribution, and reproduction in any medium, provided the original author and source are credited. 
Since the measurements were non-invasive, the technique is commonly used in the clinic and is readily available to laymen, and the treatment was pre-agreed between the physiotherapist and the patients, no ethics committee approval was deemed necessary. The participants gave their informed written consent to participate in the study, which was carried out according to the Helsinki Declaration (http://www. wma.net/en/30publications/10policies/b3/).

\section{Design}

mfBIA measurements were carried out on the following muscles: $\mathrm{m}$. sternocleidomastoideus, $\mathrm{m}$. trapezius, upper back, lower back, $\mathrm{m}$. vastus lateralis, and $\mathrm{m}$. gastrocnemius, using an ImpediMed Inc tetra bipolar bioimpedance spectroscopy unit (Imp SFB7; Pinkenba, Qld, Australia). With this setup, 256 frequencies between 4 and $1000 \mathrm{kHz}$ with a constant current were applied. For each individual measurement, a repeated analysis was made 6 times with a 1 second interval between each analysis. $\mathrm{Ag} / \mathrm{AgCl}$ electrodes provided by ImpediMed (Single Tab Electrodes 292-STE) were used according to the manufacturer's guidelines. The electrode position adopted involved placement of the current electrodes on the outside with the voltage-sensing electrodes on the inside, and $10 \mathrm{~mm}$ between the current and the voltage-sensing electrodes. The electrodes were placed at each end of the specific muscles measured, just prior to the tendon attachment.

The mfBIA parameters, centre frequency (fc), extracellular Resistance (Re) and intracellular Resistance (Ri) were measured directly from the full multi-frequency Cole-Cole plot. The following parameters, Impedance $(\mathrm{Z})$, Resistance $(\mathrm{R})$ and Reactance $(\mathrm{Xc})$ were measured at the generally accepted frequency for human subjects of 50 $\mathrm{kHz}$, whilst Phase Angle (PA) was calculated as the $\arctan \mathrm{Xc} / \mathrm{R}$, and the Membrane Capacitance (Mc) was determined as $1 / 2 \pi f c\left(R_{e}+R_{i}\right)$.

\section{Treatment}

AtlasBalans (AtlasBalans AB, Stockholm, Sweden) provides a deep tissue massage, which is applied through a hand-held, batterydriven device with an interchangeable head that enables more specific or more general treatment according to choice of head. A routine sequence was adopted for each of the regions selected for treatment, $\mathrm{m}$. sternocleidomastoideus and $\mathrm{m}$. trapezius, and treatment was only applied to the muscles identified as being affected e.g. high level of resting tension $(\mathrm{fc})$ or high $\mathrm{Ri}$ and low Mc values. The device was angled in such a way as to reach and follow specific myofascial structures.

\section{Data analysis}

The mfBIA data was handled using the ImpediMed Inc software. At the time of measurement the Cole-Cole plot was assessed for normal distribution to assure reliable data. Furthermore, the other available plots ( $\mathrm{R}$ and $\mathrm{Xc}$ ) were also examined to ensure use of acceptable recordings.

\section{Results}

\section{Pre-treatment results}

mfBIA results pre-treatment (Table 1 ).

\section{Centre Frequency fc}

The $\mathrm{fc}$ is the frequency that gives the maximum Xc value on the Cole-Cole plot. With a higher level of resting tension, the resulting greater density of the muscle will require a higher energy, i.e. a higher frequency, to pass through the tissue. fc therefore provides important information regarding the relative density of muscle tissue e.g. the level of resting tension in a muscle.

Case 1: The fc was substantially higher for several of the right side muscles including $\mathrm{m}$. sternocleidomastoideus, $\mathrm{m}$. longissimus thoracis, and $\mathrm{m}$. vastus lateralis, with a tendency for $\mathrm{m}$. longissimus cervicis. In contrast, the low back region showed a higher fc value for the left side, and $\mathrm{m}$. trapezius and $\mathrm{m}$. gastrocnemius had almost the same values right versus left side i.e. they were balanced. This subject showed therefore some imbalance between the left and right sides of the neck and back muscles, with a tensing up of the right hand side.

Case 2: The $\mathrm{fc}$ value was found to be higher for the right side $\mathrm{m}$. longissimus cervicis and thoracis and $\mathrm{m}$. vastus lateralis, while the $\mathrm{fc}$ values for $\mathrm{m}$. sternocleidomastoideus, and $\mathrm{m}$. trapezius were higher on the left side. The low back region and $\mathrm{m}$. gastrocnemius were almost balanced right versus left. The pattern here suggests that the two sides of the neck/back region were pulling in different directions left versus right sides, which would be expected to result in some degree of torsion in this region, although the aspect of compensation cannot be completely ignored.

Both cases quite clearly showed muscle involvement in their pain condition.

\section{Impedance $Z$ and Resistance $R$}

A combined assessment of the $\mathrm{Z}$ and $\mathrm{R}$ values for a muscle can help determine a swelling/oedema or a dehydrated state as well as provide details regarding muscle mass. When looking at the different muscles assessed here, the values $\mathrm{Z}$ and $\mathrm{R}$ were almost identical in both subjects, both for the right and left sides of the muscles, which indicates that there is no signs of oedema or swelling or dehydration. These data suggest that there is no great degree of inflammation or overuse of the muscles measured.

\section{Membrane Capacitance Mc}

The membrane capacitance $(\mathrm{Mc})$ indicates the status of the membrane potential, and hence muscle fibre health, as well as the transport status over the membrane.

Case 1: There was a slight to almost no difference for the right versus left side when looking at $\mathrm{m}$. sternocleidomastoideus, $\mathrm{m}$. longissimus cervicis and $\mathrm{m}$. gastrocnemius, while the Mc was higher for the left side for $\mathrm{m}$. trapezius, $\mathrm{m}$. longissimus thoracis and $\mathrm{m}$. vastus lateralis, indicating higher metabolic activity in these muscles on the left hand side. A very large left-right difference was seen for the low back region muscles where $\mathrm{Mc}$ was measured to be almost twice the value for the right side versus the left side. The interesting observation here is that where there is a substantially higher $\mathrm{fc}$ between the left and right sides, a lower $\mathrm{Mc}$ is found compared to a muscle with a normal resting tension, indicating that the more tense a muscle is the more metabolically active it presents, most likely a form of compensation?

Case 2: Mc was likewise found to be lower for those muscles measured as having a higher $\mathrm{fc}$.

\section{Intracellular Resistance $\mathrm{Ri}$ and extracellular resistance $\mathrm{Re}$}

Ri has been shown to be correlated with VO2-max at rest [18], and may therefore be taken as an index of a muscle's anabolic status [18]. Re may, on the other hand, be used as a measure of dehydration in cases where impaired perfusion is not expected [9].

Case 1: Ri was found to differ between the left and right sides in 
Citation: Fener DK, Bartels EM, Elbrond VS, Harrison AP (2016) Chronic Neck Pain Assessment using Multi-Frequency Bioimpedance. Physiother Rehabil 1: 113. doi: 10.4172/2573-0312.1000113

Page 3 of 6

\begin{tabular}{|c|c|c|c|c|c|c|c|c|c|c|c|c|c|c|}
\hline \multirow[t]{2}{*}{ Case 1} & \multicolumn{2}{|c|}{$\frac{\mathrm{m} .}{\text { sternocleidomastoid }}$} & \multicolumn{2}{|c|}{ m. trapezius } & \multicolumn{2}{|c|}{$\begin{array}{l}\text { m. longissimus } \\
\text { cervicis }\end{array}$} & \multicolumn{2}{|c|}{$\begin{array}{l}\text { m. longissimus } \\
\text { thoracis }\end{array}$} & \multicolumn{2}{|c|}{$\begin{array}{l}\text { m. vastus } \\
\text { lateralis }\end{array}$} & \multicolumn{2}{|c|}{ m. gastrocnemius } & \multicolumn{2}{|l|}{$\begin{array}{l}\text { low } \\
\text { back }\end{array}$} \\
\hline & Left & Right & Left & Right & Left & Right & Left & Right & Left & Right & Left & Right & Left & Right \\
\hline$Z \Omega$ & 82.4 & 76.9 & 99.7 & 111.3 & 98.9 & 98.1 & 86.8 & 105.9 & 165.2 & 153.5 & 107.3 & 101.6 & 110.6 & 94.8 \\
\hline $\mathrm{R} \Omega$ & 81.6 & 76.3 & 99.0 & 110.8 & 98.4 & 97.4 & 86.1 & 105.3 & 164.8 & 153.2 & 106.2 & 100.4 & 110.4 & 94.5 \\
\hline $\mathrm{Xc} \Omega$ & 11.1 & 9.9 & 11.6 & 10.7 & 10.7 & 11.4 & 10.7 & 11.4 & 11.9 & 9.3 & 15.8 & 15.9 & 6.6 & 7.1 \\
\hline $\begin{array}{l}\text { Phase } \\
\text { Angle }^{\circ}\end{array}$ & 7.7 & 7.4 & 6.7 & 5.5 & 6.2 & 6.7 & 7.1 & 6.2 & 4.1 & 3.5 & 8.5 & 9.0 & 3.4 & 4.3 \\
\hline fc $k H z$ & 69.1 & 77.8 & 69.2 & 68.2 & 71.7 & 74.6 & 65.8 & 83.7 & 38.1 & 58.1 & 50.8 & 49.1 & 39.2 & 32.0 \\
\hline $\operatorname{Re} \Omega$ & 101.0 & 91.2 & 116.8 & 128.2 & 113.2 & 112.1 & 104.0 & 120.3 & 189.4 & 167.4 & 129.1 & 124.4 & 126.9 & 115.3 \\
\hline $\mathrm{Mc} n \mathrm{nF}$ & 10.0 & 9.0 & 7.0 & 5.7 & 6.2 & 6.2 & 9.0 & 5.1 & 5.1 & 2.9 & 8.5 & 9.7 & 7.8 & 14.0 \\
\hline $\operatorname{Ri} \Omega$ & 128.8 & 136.3 & 211.7 & 284.1 & 246.9 & 232.7 & 165.7 & 253.3 & 627.3 & 788.4 & 240.8 & 209.8 & 395.9 & 241.0 \\
\hline \multirow[t]{2}{*}{ Case 2} & \multicolumn{2}{|c|}{$\frac{\mathrm{m} .}{\text { sternocleidomastoid }}$} & \multicolumn{2}{|c|}{ m. trapezius } & \multicolumn{2}{|c|}{$\begin{array}{l}\text { m. longissimus } \\
\text { cervicis }\end{array}$} & \multicolumn{2}{|c|}{$\begin{array}{l}\text { m. longissimus } \\
\text { thoracis }\end{array}$} & \multicolumn{2}{|c|}{$\begin{array}{l}\text { m. vastus } \\
\text { lateralis }\end{array}$} & \multicolumn{2}{|c|}{ m. gastrocnemius } & \multicolumn{2}{|l|}{$\begin{array}{l}\text { low } \\
\text { back }\end{array}$} \\
\hline & Left & Right & Left & Right & Left & Right & Left & Right & Left & Right & Left & Right & Left & Right \\
\hline$Z \Omega$ & 92.1 & 87.9 & 100.4 & 91.6 & 91.4 & 104.2 & 95.5 & 101.9 & 159.1 & 172.9 & 136.0 & 129.8 & 61.0 & 65.3 \\
\hline $\mathbf{R} \Omega$ & 90.9 & 87.2 & 100.1 & 91.3 & 90.6 & 103.5 & 94.8 & 101.3 & 158.5 & 172.4 & 134.2 & 128.1 & 60.6 & 65.0 \\
\hline Xc $\Omega$ & 15.1 & 10.8 & 8.4 & 7.0 & 12.5 & 12.0 & 11.6 & 11.2 & 14.1 & 13.7 & 22.3 & 20.8 & 6.3 & 6.3 \\
\hline $\begin{array}{l}\text { Phase } \\
\text { Angle }\end{array}$ & 9.4 & 7.1 & 4.8 & 4.4 & 7.9 & 6.6 & 7.0 & 6.3 & 5.1 & 4.5 & 9.4 & 9.2 & 5.9 & 5.5 \\
\hline fc $\mathbf{k H z}$ & 81.4 & 73.8 & 92.8 & 84.0 & 81.0 & 89.7 & 67.8 & 74.6 & 45.5 & 60.9 & 42.3 & 44.0 & 54.2 & 52.5 \\
\hline $\operatorname{Re} \Omega$ & 111.1 & 105.6 & 114.3 & 103.4 & 105.5 & 119.3 & 114.0 & 119.4 & 183.8 & 191.3 & 171.7 & 162.2 & 70.8 & 75.9 \\
\hline Mc nF & 8.3 & 8.4 & 4.9 & 5.3 & 6.9 & 5.3 & 8.0 & 6.4 & 5.0 & 3.0 & 8.7 & 8.7 & 12.3 & 11.8 \\
\hline $\operatorname{Ri} \Omega$ & 125.4 & 151.5 & 236.7 & 253.8 & 179.2 & 213.7 & 181.2 & 212.9 & 514.8 & 679.3 & 259.4 & 252.9 & 167.1 & 181.4 \\
\hline
\end{tabular}

Table 1: Pre-treatment mfBIA results.

all measured muscles to a varying degree. In general, when a large difference was found, a low Mc value was found to correlate to a high $\mathrm{Ri}$ value, indicating that the anabolic state of the muscle on the side with the high Ri differs from its counter-part (low Ri), being in a metabolically more active state.

Case 2: The largest left versus right side difference was seen for Ri in $\mathrm{m}$. vastus lateralis (right more oxygen-consumed than left side). $\mathrm{Re}$ values did not show any important differences.

\section{Post-treatment results}

mfBIA results following AtlasBalans treatment of $\mathrm{m}$. sternocleidomastoideus and trapezius (Table 2).

Two muscles were selected for AtlasBalans treatment, $\mathrm{m}$. sternocleidomastoideus and $\mathrm{m}$. trapezius. Measurements were taken directly following treatment.

\section{Effect of treatment}

The fc values in Case 1 showed a decrease of $13.6 \mathrm{kHz}$ for the right side, and $6 \mathrm{kHz}$ for the left side $\mathrm{m}$. sternocleidomastoideus. There was also a decrease in $\mathrm{fc}$ of 20.4 and $12.4 \mathrm{kHz}$ form. trapezius, left and right respectively, indicating an effect on all four muscles towards a less tense state.

The $\mathrm{Ri}$ and Mc values both increased, supporting the evidence that the treatment had led to a more relaxed, less metabolically active muscle directly after treatment.

In Case 2 the fc values showed a direct but insignificant decrease of $2.9 \mathrm{kHz}$ and $0.6 \mathrm{kHz}$ after treatment, for the left and right sides, respectively, for $\mathrm{m}$. sternocleidomastoideus. The measurements for $\mathrm{m}$. trapezius showed a decrease in $\mathrm{fc}$ of $12.1 \mathrm{kHz}$ for the left side and an increase of $5 \mathrm{kHz}$ for the right side.

When comparing changes in the Ri and Mc values, some decrease was seen, but this was not as convincing as for Case 1, and the effect of treatment was therefore not as clear cut as that of Case 1.

\section{Discussion}

In groups of neck-pain patients, it is difficult to determine why some individuals develop chronic pain and some do not. A recent Cochrane review reports that "Neck pain is multifactorial in its etiology and factors contributing to its development include age, gender, a history of neck pain, the occurrence of other musculoskeletal problems, poor posture, repetitive strain, poor self-rated health, and social and psychological factors" [19]. Indeed, this very broad description of the underlying causes may in itself provide some of the answers as to the very different outcomes between patients in this group.

Several types of interventions for chronic neck patients exist, but the effect of these is not always well documented due to a varying quality of studies concerning these therapies [13]. The Cochrane Collaboration has provided systematic reviews of some of these interventions, such as exercise [15], massage for mechanical neck disorders [20], patient education for neck pain [21], electrotherapy for neck pain [22], mechanical traction for neck pain with or without radiculopathy [23], and conservative treatment for whiplash [24]. The overall conclusion of the reviews is that the evidence for positive effects of treatment is low, 


\begin{tabular}{|c|c|c|c|c|c|c|c|c|c|}
\hline \multirow[t]{2}{*}{ Case 1} & \multicolumn{2}{|c|}{ m. sternocleidomastoid } & \multicolumn{2}{|c|}{ m. trapezius } & \multirow[t]{2}{*}{ Case 2} & \multicolumn{2}{|c|}{ m. sternocleidomastoid } & \multicolumn{2}{|c|}{ m. trapezius } \\
\hline & LH & $\mathbf{R H}$ & LH & RH & & LH & RH & LH & $\mathbf{R H}$ \\
\hline$Z \Omega$ & 82.4 & 76.9 & 99.7 & 111.3 & $Z \Omega$ & 92.1 & 87.9 & 100.4 & 91.6 \\
\hline $\mathrm{R} \Omega$ & 81.6 & 76.3 & 99.0 & 110.8 & $\mathrm{R} \Omega$ & 90.9 & 87.2 & 100.1 & 91.3 \\
\hline $\mathrm{Xc} \Omega$ & 11.1 & 9.9 & 11.6 & 10.7 & $\mathrm{Xc} \Omega$ & 15.1 & 10.8 & 8.4 & 7.0 \\
\hline Phase Angle ${ }^{\circ}$ & 7.7 & 7.4 & 6.7 & 5.5 & Phase Angle ${ }^{\circ}$ & 9.4 & 7.1 & 4.8 & 4.4 \\
\hline fc $\mathrm{kHz}$ & 69.1 & 77.8 & 69.2 & 68.2 & fc $\mathrm{kHz}$ & 81.4 & 73.8 & 92.8 & 84.0 \\
\hline $\operatorname{Re} \Omega$ & 101.0 & 91.2 & 116.8 & 128.2 & $\operatorname{Re} \Omega$ & 111.1 & 105.6 & 114.3 & 103.4 \\
\hline Mc nF & 10.0 & 9.0 & 7.0 & 5.7 & Mc nF & 8.3 & 8.4 & 4.9 & 5.3 \\
\hline Ri $\Omega$ & 128.8 & 136.3 & 211.7 & 284.1 & $\operatorname{Ri} \Omega$ & 125.4 & 151.5 & 236.7 & 253.8 \\
\hline After treatment & LH & $\mathbf{R H}$ & LH & RH & After treatment & LH & RH & LH & RH \\
\hline$Z \Omega$ & 70.1 & 81.1 & 105.6 & 114.2 & $\mathrm{Z} \Omega$ & 94.6 & 87.6 & 109.9 & 105.0 \\
\hline $\mathbf{R} \Omega$ & 68.8 & 80.0 & 105.1 & 113.5 & $\mathbf{R} \Omega$ & 93.4 & 86.8 & 109.0 & 104.3 \\
\hline $\mathrm{Xc} \Omega$ & 13.3 & 13.5 & 11.0 & 12.4 & $\mathrm{Xc} \Omega$ & 15.1 & 13.4 & 13.5 & 12.0 \\
\hline Phase Angle ${ }^{\circ}$ & 10.9 & 9.6 & 6.0 & 6.2 & Phase Angle ${ }^{\circ}$ & 9.2 & 8.8 & 7.1 & 6.6 \\
\hline fc $k H z$ & 55.5 & 71.8 & 48.8 & 55.8 & fc $k H z$ & 78.5 & 73.2 & 80.7 & 89.0 \\
\hline $\operatorname{Re} \Omega$ & 90.1 & 100.4 & 130.5 & 139.0 & $\operatorname{Re} \Omega 1$ & 114.9 & 111.7 & 126.3 & 120.1 \\
\hline Mc nF & 15.7 & 10.6 & 9.7 & 7.9 & Mc nF & 8.4 & 10.0 & 5.5 & 5.3 \\
\hline $\operatorname{Ri} \Omega$ & 92.8 & 108.7 & 205.4 & 222.5 & $\operatorname{Ri} \Omega$ & 127.4 & 104.8 & 231.8 & 216.9 \\
\hline
\end{tabular}

Table 2: mfBIA results following AtlasBalans treatment of $m$. sternocleidomastoideus and trapezius.

and that no definite statements on the efficacy and clinical usefulness of these treatments can be made.

A major cause behind this conclusion may very well be the lack of use of objective measurements to identify the involved muscles in chronic neck patients, where muscle involvement is often the case. In this study, and in earlier studies by Bartels et al. [9] and Nescolarde et al. [10], mfBIA has been demonstrated as a method to identify asymmetry of muscle pairs, as well as metabolic state and degree of tension of muscles which were suspected to be involved in the neck condition. Applying mfBIA could therefore help providing a clear diagnosis of the cause behind the neck pain. It would then further be possible to focus the right treatment towards the involved tissue, and thereby change from a more general approach towards patient-focused treatment.

The two cases in this study were randomly selected with the diagnosis of 'chronic neck pain' for a period of more than 6 months, and the planned treatment, in common. The aspect of the mechanism/ accident connected with the development of chronic neck pain was different in the two cases.

The literature presents a large number of potential (specific) causes of neck pain [3,25-30]. These vary from trauma (especially motor vehicle accidents) to infections, tumours, congenital disorders and inflammation. In the vast majority of cases, however, no specific underlying pathology can be established and the complaints are labelled as "non-specific neck pain" [26]. With this in mind, it would be of great value if more measurable common pathologies could indicate a set of treatment options, which could have a positive effect on the condition.

With the diagnosis and treatment of chronic neck pain being so difficult, especially when labelled as "non-specific", our hope was that mfBIA could be a more objective measure of the particular patient's condition. A reliable diagnostic method could perhaps even counteract the finding of Borghouts et al. who showed that once "non-specific neck pain" has become chronic, only $44 \%$ of the patients seek help from their general practitioner on a yearly basis [31].

\section{Measurement with mfBIA in chronic neck pain patients}

mfBIA is a known and tested method [9,32,33], often used in sports clinics, but it has as far as we know not yet been implemented in the diagnosis of chronic neck pain. It is possible with mfBIA to measure asymmetrical muscle tension, as well as ascertain whether there is oedema/dehydration or suspicion of inflammation in those muscles measured $[9,32,34]$. With mfBIA it is therefore possible to identify muscles which could be part of the underlying cause behind chronic neck pain and thereby focus the treatment on the involved muscles before the condition becomes chronic, a process that involves pain hypersensitization [35-38]. This latter component may in parallel be assessed with the Pain Detect Questionnaire $[39,40]$.

Muscles do not operate as completely independent units, but are interconnected via the myofascial system [19]. The mfBIA assessment must therefore, as with this case study, include measurements of myofascial linked muscles for example neck, back, hip and leg muscles, since myofascial damage may also be an underlying cause. In the two cases reported in this paper, left-right asymmetry in some of these linked muscles was found, although the patients complained about neck pain. This is important knowledge for the clinicians and therapist who, based on mfBIA measurements, finally have the possibility of directing forms of treatment towards those parts of the body where problems have been identified.

\section{Treatment of chronic neck pain}

A common choice of treatment for patients with non-specific chronic neck pain is physiotherapy. General practitioners did, according 
Citation: Fener DK, Bartels EM, Elbrond VS, Harrison AP (2016) Chronic Neck Pain Assessment using Multi-Frequency Bioimpedance. Physiother Rehabil 1: 113. doi: 10.4172/2573-0312.1000113

Page 5 of 6

to a study by Borghouts and colleagues, refer $51 \%$ of their patients with chronic neck pain for physiotherapy treatment [31].

In a Cochrane review looking at whether massage had positive effects in patients with mechanical neck disorders, very low level of evidence that certain massage techniques may have been more effective than control or placebo treatment in improving function and tenderness was found [41]. However, others report that massage and manipulation of affected muscles can have a positive effect on myofascial pain [42].

In a study of 6 horses with movement problems, measurements involving mfBIA revealed increased myofascial tonus and stiffness in certain regions. The identified regions and specific muscles were subsequently treated using a form of AtlasBalans, AtlasOrange 1, and measured 1, 24 and 48 hours post treatment, once again using mfBIA. The effect of AtlasBalans treatment was in these cases found to be relatively rapid and effective according to the bioimpedance results [43].

The AtlasBalans treatment did seem to create a positive change in one of our patients, to such an extent in fact that the patient sought to continue the treatment, while it is difficult to say how successful the treatment was for the other patient. Perhaps of greater importance, though, is the fact that mfBIA is an easily applicable and non-invasive method to look at possible involvement of interlinked muscles in chronic neck pain, thereby providing a more overall view of the patient's condition when considering treatment choices.

\section{Conclusions}

mfBIA was proven to be an easily applicable non-invasive method for objective measurement of muscle involvement in patients with chronic neck pain.

AtlasBalans treatment did not show any clear indication as being an efficient form of treatment in terms of relieving muscle tension in these patients.

We conclude that mfBIA measurement of potentially involved muscles in patients with chronic neck pain, prior to treatment, can help to direct treatment towards those muscles believed to be involved in this condition. This may reduce the risk of developing pain hypersensitization and address at least part of the underlying causes for the presented condition.

\section{Acknowledgement}

The study was supported by the OAK Foundation (to EMB), OAK Grant: OCAY-13-309.

\section{References}

\section{Binder Al (2008) Neck pain. BMJ Clin Evid 2008.}

2. Croft PR, Lewis M, Papageorgiou AC, Thomas E, Jayson MI, et al. (2001) Risk factors for neck pain: a longitudinal study in the general population. Pain 93: 317-325

3. Hogg-Johnson S, Vand V, Carroll LJ, Holm LW, Cassidy JD, et al. (2009) The burden and determinants of neck pain in the general population: results of the Bone and Joint Decade 2000-2010 Task Force on Neck Pain and Its Associated Disorders. J Manipulative Physiol Ther 32: S70-S86.

4. Becker N, Thomsen AB, Olsen AK, Sjøgren P, Bech P, et al. (1997) Pain epidemiology and health related quality of life in chronic non-malignant pain patients referred to a Danish multidisciplinary pain center. Pain 73: 393-400.

5. Carroll LJ, Holm LW, Hogg-Johnson S, Cote P, Cassidy JD, et al. (2009) Course and prognostic factors for neck pain in whiplash-associated disorders (WAD): results of the Bone and Joint Decade 2000-2010 Task Force on Neck Pain and Its Associated Disorders. J Manipulative Physiol Ther 32: S97-S107.

6. Rezai M, Côté P, Cassidy JD, Carroll L (2009) The association between prevalent neck pain and health-related quality of life: a cross-sectional analysis Eur Spine J 18: 371-381

7. Borghouts JA, Koes BW, Vondeling H, Bouter LM (1999) Cost-of-illness of neck pain in The Netherlands in 1996. Pain 80: 629-636.

8. Oddsdóttir GL, Kristjansson E, Gislason MK (2015) Sincerity of effort versus feigned movement control of the cervical spine in patients with whiplashassociated disorders and asymptomatic persons: a case-control study Physiother Theory Pract 31: 403-409.

9. Bartels EM, Sørensen ER2, Harrison AP3 (2015) Multi-frequency bioimpedance in human muscle assessment. Physiol Rep 3.

10. Nescolarde L, Yanguas J, Lukaski H, Alomar X, Rosell-Ferrer J, et al. (2013) Localized bioimpedance to assess muscle injury. Physiol Meas 34: 237-245.

11. Gross AR, Hoving JL, Haines TA, Goldsmith CH, Kay T, et al. (2004) A Cochrane review of manipulation and mobilization for mechanical neck disorders. Spine 29: $1541-1548$.

12. Bryans R, Decina P, Descarreaux M, Duranleau M, Marcoux H, et al. (2014) Evidence-based guidelines for the chiropractic treatment of adults with neck pain. J Manipulative Physiol Ther 37: 42-63.

13. Damgaard P, Bartels EM, Ris I, Christensen R, Juul-Kristensen B (2013) Evidence of Physiotherapy Interventions for Patients with Chronic Neck Pain A systematic review of randomized controlled trials. ISRN Pain: ID 567175.

14. Kay TM, Gross A, Goldsmith CH, Rutherford S, Voth S, et al. (2012) Exercises for mechanical neck disorders. Cochrane Database Syst Rev : CD004250.

15. Gross A, Kay TM, Paquin JP, Blanchette S, Lalonde P, et al. (2015) Exercises for mechanical neck disorders. Cochrane Database Syst Rev 1: CD004250.

16. Murphy B, Taylor HH, Marshall P (2010) The effect of spinal manipulation on the efficacy of a rehabilitation protocol for patients with chronic neck pain: a pilot study. J Manipulative Physiol Ther 33: 168-177.

17. Myers TW (2009) Anatomy trains, myofascial meridians for manual and movement therapists $\left(2^{\text {nd }}\right.$ edn.) Elsevier, Edinburg.

18. Stahn A, Strobel G, Terblanche E (2008) VO(2max) prediction from multifrequency bioelectrical impedance analysis. Physiol Meas 29: 193-203.

19. Monticone M, Ambrosini E, Cedraschi C, Rocca B, Fiorentini R, et al. (2015) Cognitive-behavioral Treatment for Subacute and Chronic Neck Pain: A Cochrane Review. Spine (Phila Pa 1976) 40: 1495-1504.

20. Haraldsson BG, Gross AR, Myers CD, Ezzo JM, Morien A, et al. (2006) Massage for mechanical neck disorders. Cochrane Database Syst Rev : CD004871.

21. Gross A, Forget M, St George K, Fraser MM, Graham N, et al. (2012) Patient education for neck pain. Cochrane Database Syst Rev : CD005106.

22. Kroeling P, Gross A, Graham N, Burnie SJ, Szeto G, et al. (2013) Electrotherapy for neck pain. Cochrane Database Syst Rev : CD004251.

23. Graham N, Gross A, Goldsmith CH, Klaber Moffett J, Haines T, et al. (2008) Mechanical traction for neck pain with or without radiculopathy. Cochrane Database Syst Rev : CD006408.

24. Verhagen AP, Scholten-Peeters GG, van Wijngaarden S, de Bie RA, BiermaZeinstra SM (2007) Conservative treatments for whiplash. Cochrane Database Syst Rev : CD003338.

25. Alexander EP (2011) History, physical examination, and differential diagnosis of neck pain. Phys Med Rehabil Clin N Am 22: 383-393, vii.

26. Cagnie B1, Danneels L, Van Tiggelen D, De Loose V Cambier D (2007) Individual and work related risk factors for neck pain among office workers: a cross sectional study. Eur Spine J 16: 679-686.

27. Christensen JO, Knardahl S (2010) Work and neck pain: a prospective study of psychological, social, and mechanical risk factors. Pain 151: 162-173.

28. Misailidou V, Malliou P, Beneka A, Karagiannidis A, Godolias G (2010) Assessment of patients with neck pain: a review of definitions, selection criteria, and measurement tools. J Chiropr Med 9: 49-59.

29. Paksaichol A, Lawsirirat C, Janwantanakul P (2015) Contribution of biopsychosocial risk factors to nonspecific neck pain in office workers: A path analysis model. J Occup Health 57: 100-109.

30. Ståhl MK, El-Metwally AA, Mikkelsson MK, Salminen JJ, Pulkkinen LR, et al 
Citation: Fener DK, Bartels EM, Elbrond VS, Harrison AP (2016) Chronic Neck Pain Assessment using Multi-Frequency Bioimpedance. Physiother Rehabil 1: 113. doi: 10.4172/2573-0312.1000113

Page 6 of 6

(2013) Genetic and environmental influences on non-specific neck pain in early adolescence: a classical twin study. Eur J Pain 17: 791-798.

31. Borghouts J, Janssen H, Koes B, Muris J, Metsemakers J, et al. (1999) The management of chronic neck pain in general practice. A retrospective study. Scand J Prim Health Care 17: 215-220.

32. Nescolarde L, Yanguas J, Lukaski H, Alomar X, Rosell-Ferrer J, et al. (2015) Effects of muscle injury severity on localized bioimpedance measurements. Physiol Meas 36: 27-42.

33. Harrison AP, Elbrønd VS, Riis-Olesen K, Bartels EM (2015) Multi-frequency bioimpedance in equine muscle assessment. Physiol Meas 36: 453-464.

34. Nescolarde L, García-González MA, Rosell-Ferrer J, Doñate T, Querfeld U (2006) Thoracic versus whole body bioimpedance measurements: the relation to hydration status and hypertension in peritoneal dialysis patients. Physiol Meas 27: 961-971.

35. Vladimirova $N$, Jespersen A, Bartels EM, Christensen AW, Bliddal $H$, et al. (2015) Pain Sensitisation in Women with Active Rheumatoid Arthritis: A Comparative Cross-Sectional Study. Arthritis 2015: 434109

36. Rifbjerg-Madsen S, Christensen AW, Boesen M, Christensen R, DanneskioldSamsøe B, et al. (2014) Can the painDETECT Questionnaire score and MRI help predict treatment outcome in rheumatoid arthritis: protocol for the
Frederiksberg hospital's Rheumatoid Arthritis, pain assessment and Medical Evaluation (FRAME-cohort) study. BMJ Open 4: e006058.

37. Jespersen A, Amris K, Graven-Nielsen T, Arendt-Nielsen L, Bartels EM, et al. (2013) Assessment of pressure-pain thresholds and central sensitization of pain in lateral epicondylalgia. Pain Med 14: 297-304.

38. Curatolo M1, Arendt-Nielsen L, Petersen-Felix S (2006) Central hypersensitivity in chronic pain: mechanisms and clinical implications. Phys Med Rehabil Clin N Am 17: 287-302.

39. Freynhagen R, Baron R, Gockel U, Tölle TR (2006) painDETECT: a new screening questionnaire to identify neuropathic components in patients with back pain. Curr Med Res Opin 22: 1911-1920.

40. Jespersen A, Amris K, Bliddal H, Andersen S, Lavik B, et al. (2010) Is neuropathic pain underdiagnosed in musculoskeletal pain conditions? The Danish PainDETECTive study. Curr Med Res Opin 26: 2041-2045.

41. Stecco A, Gesi M, Stecco C, Stern R (2013) Fascial components of the myofascial pain syndrome. Curr Pain Headache Rep 17: 352.

42. Patel KC, Gross A, Graham N, Goldsmith CH, Ezzo J, et al. (2012) Massage for mechanical neck disorders. Cochrane Database Syst Rev : CD004871.

43. Elbrønd VS (2015) Multi-frequency bioimpedance and myofascial release therapy: An equine "AtlasOrange1" validation study. Medical Research Archive. 